\title{
Similar long-term results of mitral valve repair for anterior compared with posterior leaflet prolapse
}

\author{
Michele De Bonis, MD, ${ }^{a}$ Roberto Lorusso, MD, PhD, ${ }^{b}$ Elisabetta Lapenna, MD, ${ }^{\text {a }}$ Samer Kassem, MD, ${ }^{a}$ \\ Giuseppe De Cicco, MD, ${ }^{\mathrm{b}}$ Lucia Torracca, MD, ${ }^{\text {a }}$ Francesco Maisano, MD, ${ }^{\mathrm{a}}$ Giovanni La Canna, MD, ${ }^{\mathrm{a}}$ and \\ Ottavio Alfieri, MDa
}

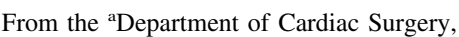
San Raffaele University Hospital, Milan, and ${ }^{\mathrm{b} C a r d i a c}$ Surgery Unit, Civic Hospital, Brescia, Italy.

Read at the Thirty-first Annual Meeting of The Western Thoracic Surgical Association, Victoria, BC, Canada, June 22-25, 2005.

Received for publication June 15, 2005; revisions received Sept 27, 2005; accepted for publication Sept 30, 2005.

Address for reprints: Michele De Bonis, MD, Department of Cardiac Surgery, San Raffaele University Hospital, Via Olgettina 60, 20132 Milano, Italy (E-mail: michele. debonis@hsr.it).

J Thorac Cardiovasc Surg 2006;131:364-70

$0022-5223 / \$ 32.00$

Copyright $\odot 2006$ by The American Association for Thoracic Surgery

doi:10.1016/j.jtcvs.2005.09.040
}

Objective: The results of mitral valve repair for anterior leaflet prolapse have been less gratifying than those reported for posterior leaflet prolapse. We compared the long-term durability of 2 different surgical techniques: the edge-to-edge repair, which is used for the treatment of anterior leaflet prolapse, and quadrangular resection, which has been adopted for correction of posterior leaflet prolapse.

Methods: From 1991 through April 2004, 133 patients with anterior leaflet prolapse and 605 with posterior leaflet prolapse caused by degenerative mitral disease underwent valve repair. The edge-to-edge repair was used for correction of anterior leaflet prolapse, and quadrangular resection of the posterior leaflet, with or without sliding plasty, was used for correction of posterior leaflet prolapse. All patients received a concomitant annuloplasty procedure.

Results: No hospital deaths occurred in the anterior leaflet prolapse group, whereas $2(0.3 \%)$ patients died in the posterior leaflet prolapse group $(P=.7)$. Follow-up was $100 \%$ and $97.2 \%$ complete in the anterior and posterior leaflet prolapse groups, respectively. At 10 years, overall survival was $91 \% \pm 4.06 \%$ for anterior leaflet prolapse and $93.5 \% \pm 1.81 \%$ for posterior leaflet prolapse $(P=.18)$, and freedom from cardiac death was $95.8 \% \pm 2.83 \%$ for anterior leaflet prolapse and $97.4 \% \pm$ $0.95 \%$ posterior leaflet prolapse $(P=.27)$. Freedom from reoperation was $96 \% \pm$ $2.3 \%$ in the anterior leaflet prolapse group and $96.5 \% \pm 1.18 \%$ in the posterior leaflet prolapse group $(P=.37)$. At follow-up (mean, $4.5 \pm 3.12$ years; range, 1 month-13.2 years), New York Heart Association functional class I or II was documented in $93.2 \%$ of patients in the anterior leaflet prolapse group and $92.8 \%$ in the posterior leaflet prolapse group $(P=.98)$.

Conclusions: The long-term results of the edge-to-edge repair in the setting of anterior leaflet prolapse are similar to those obtained with quadrangular resection for the treatment of posterior leaflet prolapse.

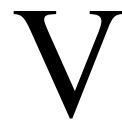

alve repair represents the gold standard for surgical correction of degenerative mitral regurgitation (MR). Compared with prosthetic replacement, it provides lower hospital mortality, ${ }^{1-3}$ longer survival, better preservation of ventricular function, ${ }^{2,45}$ fewer thromboembolic complications, and reduced risk of endocarditis. ${ }^{6}$ The predominant lesion leading to degenerative MR is posterior leaflet prolapse (PLP), which can be effectively corrected by means of quadrangular resection of the prolapsing segment with highly reproducible and durable results. ${ }^{7}$ Segmental anterior leaflet prolapse (ALP), on the other hand, although less common, is usually corrected by more demanding surgical techniques, such as chordal shortening, chordal transposition, chordal replacement, and papillary muscle repositioning. ${ }^{8-12}$ As a matter of fact, in many series the long-term results of correction of ALP have been less predictable and gratifying than those reported for PLP. ${ }^{7,13,14}$ 


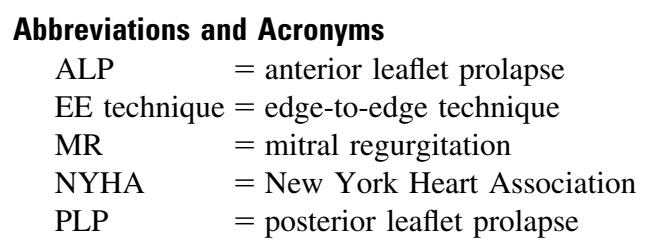

Since 1991, segmental prolapse of the anterior leaflet has been treated by us with the edge-to-edge (EE) technique with very satisfactory long-term results. ${ }^{15} \mathrm{We}$ hypothesized that the EE repair, in our experience, had been able to neutralize the ALP as an incremental risk factor for mitral valve repair failure. To test this hypothesis, we compared the long-term results of the EE technique used for the treatment of isolated segmental ALP with those obtained with the quadrangular resection adopted for correction of segmental PLP.

\section{Patients and Methods \\ Patients}

According to our hospital databases, from 1991 through April 2004, 851 patients with severe MR caused by isolated prolapse of the anterior or posterior leaflet underwent primary mitral valve repair. All their operative notes were reviewed. For the purpose of this study, only those undergoing the isolated EE technique for correction of ALP and quadrangular resection for treatment of PLP, followed by annuloplasty, were selected. Therefore 113 patients were excluded according to one or more of the following criteria: cause of mitral disease other than degenerative, mitral repair without annuloplasty, concomitant use of other repair techniques, presence of more than a single segmental prolapse of the anterior or posterior leaflet, associated aortic disease, or aortic or tricuspid replacement. Patients with functional tricuspid insufficiency treated with a conservative procedure and those with associated incidental coronary artery disease or atrial septal defect were retained. Of 738 patients representing the selected study group, 133 had isolated segmental ALP, and 605 had segmental PLP. Patients with both ALP and PLP were not included in this study. The preoperative characteristics of the 2 groups of patients were not significantly different (Table 1).

\section{Operative Technique}

All operations were carried out through a conventional median sternotomy with normothermic cardiopulmonary bypass and blood cardioplegia, with the exception of 29 young patients ( 8 in the ALP group and 21 in the PLP group) in whom a minimally invasive approach was preferred. The mitral valve was exposed through the left atrium, with the incision done in the interatrial groove. In the PLP group posterior chordal rupture-elongation in correspondence of P2 was always treated with standard quadrangular resection. A sliding plasty was associated in $43(7.1 \%)$ patients because of the presence of a high and redundant posterior leaflet to reduce the risk of postoperative systolic anterior motion of the anterior leaflet.

In the ALP group correction of MR was always performed with the EE technique, as previously described. ${ }^{16}$ In 101 pa- tients with prolapse or flail of A2, the EE suture was placed in (or close to) the central portion of the leaflets (double-orifice repair), whereas in 32 patients with either A1 or A3 lesions, the approximation of the free edges of the leaflets was carried out laterally, in continuity with the commissure (paracommissural repair). All patients included in this series had a concomitant annuloplasty procedure. Other concomitant cardiac operations were performed as required (Table 1).

\section{Follow-up}

In the ALP group follow-up was performed through outpatient visit and echocardiographic examination and was $100 \%$ complete. In the PLP group, on the other hand, follow-up information was available in $586(97.2 \%)$ of 603 hospital survivors and was obtained through outpatient visit in $28 \%$ and telephone contact with the patient and the referring physician in the remaining $72 \%$. An echocardiographic examination was available in $28.5 \%$ of those patients. Mean length of follow-up among all survivors was $4.5 \pm$ 3.12 years, ranging from 1 month to 13 years: $4.4 \pm 3.4$ years (median, 3.1 years) in the ALP group and $4.6 \pm 3.4$ years (median, 4.8 years $)$ in the PLP group $(P=.1)$.

\section{Statistical Analysis}

Statistical analysis was conducted with SPSS version 10.0 (SPSS Inc, Chicago, Ill) for the Windows (Microsoft Corp, Redmond, Wash) software package. The baseline characteristics and outcomes were compared by using $\chi^{2}$ analysis for categoric data and $t$ tests for continuous variables. Preoperative variables included in the models were age, sex, New York Heart Association (NYHA) functional class, preoperative ejection fraction, mechanism of MR (ALP vs PLP), type of annuloplasty, and associated coronary artery bypass grafting. Survival and freedom from events were analyzed with Kaplan-Meier actuarial methods. Comparison among groups was performed according to the log-rank method. Univariate analysis of risk factors was performed with Cox proportional hazards regression. All data are presented as means \pm standard deviation (for actuarial estimates, standard error is reported instead).

\section{Results}

\section{Mortality}

No hospital deaths occurred in the ALP group, whereas 2 $(0.3 \%)$ patients died in the PLP group $(P=.7)$. Causes of early death in the PLP group were, respectively, low output syndrome and bowel occlusion. Postoperative morbidity is reported in Table 2. In the ALP group there were 6 late deaths ( 3 were cardiac related, and 3 were not), for an actuarial overall survival of $91 \% \pm 4.06 \%$ at 10 years. In the PLP group 17 patients died after hospital discharge. The cause of death was cardiac related in 7 patients, and the actuarial overall survival was $93.5 \% \pm 1.81 \%$ at 10 years $(P$ $=.18$, ALP vs PLP). Freedom from cardiac death at 10 years was comparable in the 2 groups: $95.8 \% \pm 2.83 \%$ in the ALP group and $97.4 \% \pm 0.95 \%$ in the PLP group $(P=$ .27). 
TABLE 1. Baseline characteristics of the patients and operative data

\begin{tabular}{|c|c|c|c|}
\hline & ALP & PLP & $P$ value \\
\hline No. of patients & 133 & 605 & \\
\hline Age, y & $53.7 \pm 14.8$ & $54.1 \pm 13.8$ & .7 \\
\hline Male sex, $\mathrm{n}(\%)$ & $91(68.4)$ & $447(73.8)$ & .2 \\
\hline \multicolumn{4}{|l|}{ NYHA class, $\mathrm{n}(\%)$} \\
\hline I & $49(36.4)$ & $233(38.5)$ & .7 \\
\hline II & $43(32.3)$ & $199(32.8)$ & .9 \\
\hline III & $40(30)$ & $168(27.7)$ & 6 \\
\hline IV & $1(0.7)$ & $5(0.8)$ & 6 \\
\hline $\mathrm{AF}$ at presentation, $\mathrm{n}(\%)$ & $27(20)$ & $109(18)$ & 6 \\
\hline $\mathrm{EF}, \%$ & $56 \pm 10.3$ & $57 \pm 10.2$ & .5 \\
\hline \multicolumn{4}{|l|}{$\begin{array}{l}\text { Ring used for mitral } \\
\text { annuloplasty, } \mathrm{n}(\%)\end{array}$} \\
\hline Seguin & $92(69.1)$ & $456(75.3)$ & .1 \\
\hline Carpentier-Edwards classic & $25(18.7)$ & $80(13.2)$ & .1 \\
\hline Flexible Duran & $6(4.5)$ & $16(2.6)$ & .3 \\
\hline Autologous pericardium & $10(7.5)$ & $53(8.7)$ & .7 \\
\hline $\begin{array}{l}\text { Mean size of annuloplasty } \\
\text { ring }\end{array}$ & $34.8 \pm 3.1$ & $34.5 \pm 2.3$ & .3 \\
\hline \multicolumn{4}{|l|}{ Associated procedures, n (\%) } \\
\hline ASD correction & $3(2.2)$ & $12(1.9)$ & .8 \\
\hline CABG & $10(7.5)$ & $48(7.9)$ & .9 \\
\hline Tricuspid annuloplasty & $13(9.7)$ & $43(7.1)$ & .3 \\
\hline Radiofrequency ablation of $\mathrm{AF}$ & $12(9)$ & $59(9.7)$ & .9 \\
\hline
\end{tabular}

$>A L P$, Anterior leaflet prolapse; $P L P$, posterior leaflet prolapse; NYHA, New York Heart Association; $A F$, atrial fibrillation; $E F$, ejection fraction; $A S D$, atrial septal defect; $C A B G$, coronary artery bypass grafting.

\section{Reoperation}

Thirteen patients underwent reoperation for significant residual MR between 1 and 90 months after the initial repair: $3(2.2 \%)$ patients in the ALP group and $10(1.6 \%)$ patients in the PLP group. Freedom from reoperation at 10 years was $96.5 \% \pm 1.18 \%$ and $96 \% \pm 2.3 \%$, respectively $(P=.37$, Figure 1). In the ALP group all patients requiring reoperation had undergone double-orifice repair for A2 prolapseflail caused by either chordal rupture or elongation. One patient already had moderate residual MR at discharge and required mitral valve replacement within the following 6 months. The other 2 patients, despite an initially competent mitral valve, had severe mitral insufficiency 1 and 4 years, respectively, after the operation. In the PLP group all the patients undergoing reoperation had no or mild MR at discharge. At reoperation, all patients had successful mitral valve replacement. Univariate analysis failed to identify significant risk factors for reoperation among the variables

TABLE 2. Postoperative and late complications

\begin{tabular}{lcr}
\hline & ALP, $\mathbf{n}(\%)$ & PLP, $\mathbf{n}(\%)$ \\
\hline Postoperative morbidity & & \\
Re-exploration for bleeding & $3(2.2)$ & $11(1.8)$ \\
Acute renal failure & 0 & $2(0.3)$ \\
Stroke & 0 & $4(0.6)$ \\
Prolonged ventilatory support (>48 h) & $5(3.7)$ & $17(2.8)$ \\
Sternal rewiring & $1(0.7)$ & $5(0.8)$ \\
Late complications & & $3(0.4)$ \\
Endocarditis & $1(0.7)^{*}$ & $6(0.9)$ \\
Stroke & $2(1.5)$ & $8(1.3)$ \\
Congestive heart failure & $2(1.5)$ & $6(0.9)$ \\
Pericarditis & $1(0.7)$ & $2(0.3)$ \\
PTCA-stenting for angina & &
\end{tabular}

$>A L P$, Anterior leaflet prolapse; PLP, posterior leaflet prolapse; PTCA, percutaneous transluminal coronary angioplasty. *Minor cerebral hemorrhage. 


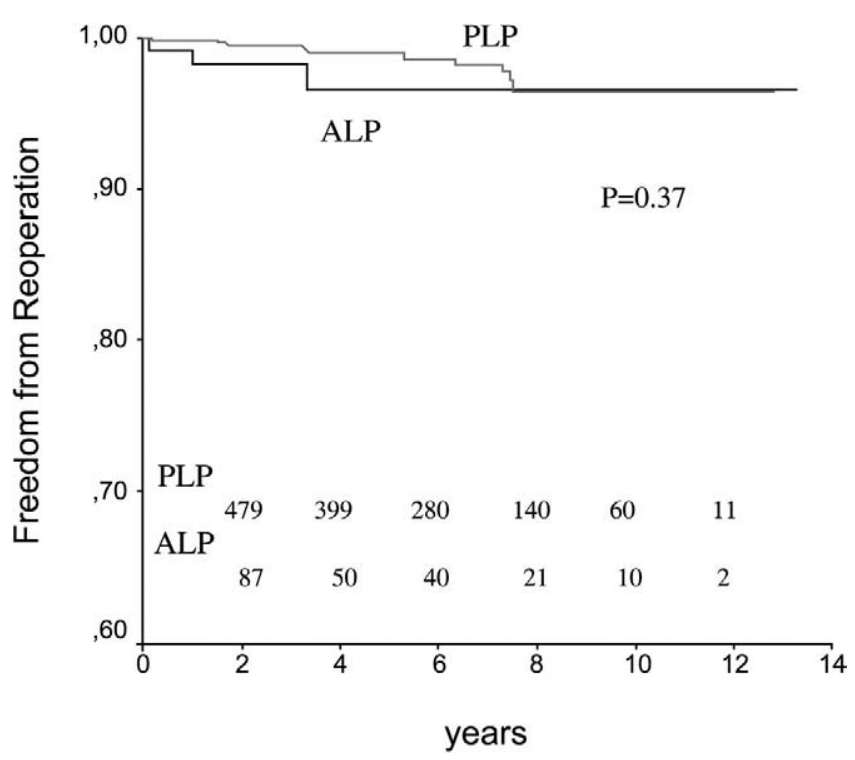

Figure 1. Actuarial overall freedom from reoperation. PLP, Posterior leaflet prolapse; $A L P$, anterior leaflet prolapse.

included in the model. In particular, the mechanism of MR (ALP vs PLP) did not influence the risk of reoperation, which was similar in the 2 groups. The type of annuloplasty had no effect on the risk of reoperation as well. Because none of the preoperative variables reached statistical significance, multivariable analysis was not performed.

\section{Morbidity}

Late complications are reported in Table 2. No patient in the ALP group experienced postoperative endocarditis. A likely endocarditis complication was reported by 3 patients in the PLP group, although such a diagnosis was rather unclear because only a telephone contact was available as followup. All of them had been successfully treated medically in their local hospital without requiring reoperation. One patient with ALP receiving warfarin therapy for chronic atrial fibrillation experienced a minor cerebral hemorrhage. In the PLP group 6 patients had a stroke. Two of them were in permanent atrial fibrillation.

\section{Echocardiographic Follow-up and Functional Status}

All patients underwent transesophageal echocardiographic control in the operating room, followed by transthoracic echocardiography at discharge. In the ALP group the mean mitral valve area after repair was $2.6 \pm 0.6 \mathrm{~cm}^{2}$ (range, $2-4$ $\mathrm{cm}^{2}$ ), and the mean mitral gradient was $3.1 \pm 1.5 \mathrm{~mm} \mathrm{Hg}$ (range, 1.8-5.8 $\mathrm{mm} \mathrm{Hg}$ ). Mitral stenosis was never detected immediately after surgical intervention or later; at the last follow-up, MR was absent or mild in $120(90.1 \%)$ patients, and the mean mitral gradient was $2.8 \pm 1.3 \mathrm{~mm} \mathrm{Hg}$ (range,
TABLE 3. Mitral regurgitation at echocardiographic follow-up

\begin{tabular}{lcc}
\hline & ALP, $\mathbf{n}(\%)$ & PLP, $\mathbf{n}(\%)$ \\
\hline $0 / 4+$ & $52(39)$ & $65(37.7)$ \\
$1+/ 4+$ & $68(51.1)$ & $92(53.4)$ \\
$2+/ 4+$ & $10(7.5)$ & $15(8.7)$ \\
$3+/ 4+$ & 0 & 0 \\
$4+/ 4+$ & $3^{*}(2.2)$ & 0 \\
& 133 & 172
\end{tabular}

$>A L P$, Anterior leaflet prolapse; $P L P$, posterior leaflet prolapse. *All 3 patients underwent reoperation.

1.6-5.4 $\mathrm{mm} \mathrm{Hg}$ ). In the PLP group an echocardiographic assessment was available at follow-up only in $172(28.5 \%)$ of 603 hospital survivors and showed results similar to those documented in the patients with ALP (Table 3). NYHA functional class I or II was present in $93.2 \%$ of patients in the ALP group and $92.8 \%$ in the PLP group $(P=.98)$. In patients with persisting symptoms, no significant mitral valve dysfunction was noted but rather some degree of preoperative LV impairment or permanent atrial fibrillation.

\section{Discussion}

This study shows that the long-term results of repair of the isolated segmental ALP by using the EE technique are similar to those observed in patients undergoing standard quadrangular resection for PLP. In our experience EE repair associated with an annuloplasty procedure has been able to neutralize the prolapse of the anterior mitral leaflet as an incremental risk factor for suboptimal results in mitral valve repair.

In degenerative MR the methods of valve reconstruction developed and popularized by Carpentier ${ }^{8,17,18}$ have achieved predictable and durable very long-term results, with an overall freedom from reoperation of $94 \%$ at 10 years and $92 \%$ at 20 years. ${ }^{14}$ The most durable repairs are obtained in patients with isolated PLP treated with quadrangular resection and annuloplasty. ${ }^{7,13,14}$ Conversely, when the anterior leaflet is involved, late results are less gratifying, and the reoperation rate is significantly higher. ${ }^{7,9-14}$ Recently, we have analyzed and reported the late outcome of a series of patients with segmental prolapse of the anterior leaflet submitted to isolated EE repair over a period of 10 years. ${ }^{15}$ The results of this study compared favorably with those described for conventional correction of ALP and were similar to those reported in the literature for patients with PLP undergoing quadrangular resection of the posterior leaflet. ${ }^{7,13,14}$ On the basis of those findings, we decided to compare the long-term results of the EE repair, used for the treatment of isolated segmental ALP, with the most standardized and durable mitral reconstructive procedure (quadrangular resection of the posterior leaflet and 
annuloplasty) in our own institution. To minimize the presence of confounding variables, we included only adult patients with degenerative MR caused by segmental prolapse of the anterior or posterior leaflet who were undergoing the isolated $\mathrm{EE}$ technique or quadrangular resection, followed by annuloplasty. Comparison of patients with ALP and PLP showed no significant difference in survival and freedom from cardiac death. Freedom from reoperation was $96 \%$ at 10 years and was similar in the 2 groups. The mechanism of MR, ALP versus PLP, and the type of annuloplasty did not influence the risk of reoperation. Univariate analysis failed to identify specific risk factors for reoperation among the variables included in the model. This is not surprising considering that some of the most common factors affecting mitral repair durability (eg, heavily calcified annulus, absence of annuloplasty, and rheumatic cause) had been excluded. The predictability of the EE technique for correction of isolated segmental ALP was demonstrated not only by the low incidence of reoperations but also by the echocardiographic examinations. Most of the patients in this series were submitted to the operation when they were still relatively asymptomatic or with few symptoms, despite severe MR. At the last follow-up, NYHA functional class I or II was documented in more than $90 \%$ of patients in both groups. We recognize that in the presence of extended prolapse of the anterior leaflet involving more than one scallop, the EE technique alone might not be sufficient to obtain a perfectly competent valve because a long suture would be required and mitral stenosis would likely be created. Under the above circumstances, the implantation of artificial chordae can be added to the EE repair to eliminate incompetence without excessively reducing the mitral valve area.

In our institution, after an experience of more than 10 years, the EE technique associated with annuloplasty remains the method of choice to correct isolated segmental prolapse of the anterior leaflet.

This study has all the limitations of every retrospective data collection. Moreover, because an echocardiographic follow-up was unavailable in the majority of the patients with PLP, we used reoperation as the primary indicator of mitral repair durability. Therefore we cannot exclude that the repair failure rate in the PLP group might have been underestimated. Another limitation of this study is represented by the fact that the causes of recurrent MR, particularly in terms of intraoperative findings, remained unknown because all reoperations were performed in other institutions. The results of this study can be applied only to patients with degenerative MR caused by isolated segmental prolapse of the anterior or posterior leaflet undergoing valve repair with annuloplasty. They cannot be extended to patients without annuloplasty, to MR of other causes, or to cases of leaflet prolapse involving more than one scallop.

\section{References}

1. Olson LJ, Subramanian R, Ackermann DM, Orszulak TA, Edwards WD. Surgical pathology of the mitral valve: a study of 712 cases spanning 21 years. Mayo Clin Proc. 1987;62:22-34.

2. Enriquez-Sarano M, Schaff HV, Orszulak TA, Tajik AJ, Bailey KR, Frye RL. Valve repair improves the outcome of surgery for mitral regurgitation. Circulation. 1995;91:1264-5.

3. Perier P, Deloche A, Chauvaud S, Fabiani JN, Rossant P, Bessou JP, et al. Comparative evaluation of mitral valve repair and replacement with Starr, Bjork, and porcine valve prostheses. Circulation. 1984; 70(suppl I):I187-92.

4. Goldman ME, Mora F, Guarino T, Fuster V, Mindich BP. Mitral valvuloplasty is superior to mitral valve replacement for preservation of left ventricular function: an intraoperative two dimensional echocardiographic study. J Am Coll Cardiol. 1987;10:568-75.

5. David TE, Burns RJ, Bacchus CM, Druck MN. Mitral valve replacement for mitral regurgitation with and without preservation of chordae tendineae. J Thorac Cardiovasc Surg. 1984;88:718-25.

6. Yun KL, Miller DC. Mitral valve repair versus replacement. Cardiol Clin. 1991;9:315-27.

7. Gillinov AM, Cosgrove DM, Blackstone EH, Diaz R, Arnold JH, Lytle BW, et al. Durability of mitral valve repair for degenerative disease. J Thorac Cardiovasc Surg. 1998;116:734-43.

8. Carpentier A. Cardiac valve surgery. The French correction. J Thorac Cardiovasc Surg. 1983;86:323-7.

9. Salati M, Moriggia S, Scrofani R, Santoli C. Chordal transposition for anterior mitral prolapse: early and long-term results. Eur J Cardiothorac Surg. 1997;11:268-73.

10. Smedira NG, Selman R, Cosgrove DM, McCarthy PM, Lytle BW, Taylor PC, et al. Repair of anterior leaflet prolapse: chordal transfer is superior to chordal shortening. J Thorac Cardiovasc Surg. 1996;112: 287-91.

11. David TE. Replacement of chordae tendineae with expanded polytetrafluoroethylene sutures. J Card Surg. 1989;4:286-90.

12. Zussa C, Polesel E, Rocco F, Valfrè C. Artificial chordae in the treatment of anterior mitral leaflet pathology. Cardiovasc Surg. 1997; 5:125-8

13. Mohty D, Orszulak TA, Schaff HV, Avierinos JF, Tajik JA, EnriquezSarano M. Very long-term survival and durability of mitral valve repair for mitral valve prolapse. Circulation. 2001;104(suppl I):I1-7.

14. Braunberger E, Deloche A, Berrei A, Abdallah F, Celestin JA, Meimoun $\mathrm{P}$, et al. Very long-term results (more than 20 years) of valve repair with Carpentier's techniques in nonrheumatic mitral valve insufficiency. Circulation. 2001;104(suppl I):I8-11.

15. Alfieri O, De Bonis M, Lapenna E, Regesta T, Maisano F, Torracca L, et al. "Edge-to-edge" repair for anterior mitral leaflet prolapse. Semin Thorac Cardiovasc Surg. 2004;16:182-7.

16. Alfieri O, Maisano F. An effective technique to correct anterior mitral leaflet prolapse. J Card Surg. 1999;14:468-70.

17. Duran CMG. Perspectives in reparative surgery for acquired valvular disease. Adv Card Surg. 1993;4:1-23.

18. Cosgrove DM, Chavez AM, Lytle BW, Gill CC, Stewart RW, Taylor PC, et al. Results of mitral valve reconstruction. Circulation. 1986; 74(suppl I):I82-7.

\section{Discussion}

Dr D. Craig Miller (Stanford, Calif). You have just heard, ladies and gentlemen, some incredibly superb results, indeed the best ever reported after mitral valve repair for myxomatous disease. If these results can be reproduced elsewhere, we should all abandon whatever we are doing today for either anterior bileaflet or posterior leaflet prolapse and switch to this operation.

Let me shed some insight on perhaps why the results are so spectacular. These are specifics that I think are important. First, you excluded $12 \%$ of the patients. One hundred thirteen patients have had complex repair, no ring, etc, and that's important. Second, 101 of these Alfieri stitches were central or A2 and 32 were 
over in the A-comm and the P-comm, a simple commissuroplasty, which we have all done, but it appears to be localized disease. Third, they're young - average age 54 years. Only $8 \%$ needed a concomitant coronary artery bypass graft. Seventy percent were in functional class I or II. This is a unique, young, minimally symptomatic or asymptomatic population. It is certainly not like the Mayo Clinic flail leaflet population, which many of the surgeons in this room may see, where $78 \%$ of the patients with flail leaflet are either over 60 years or need concomitant coronary bypass grafting. A very select population.

Enough editorializing. Let's look at this survival of $91 \%$ or $94 \%$ at 10 years. These are spectacularly good results even in this young population. How did that expected survival compare with an age- and sex-adjusted Italian or European population? A visit to Brescia or Milano might be better than a trip to Lourdes.

Dr De Bonis. Thank you, Dr Miller. Yes, I fully agree with you that this is a select population of very young patients. The thing to consider in this young age group concerns both the anterior leaflet group and the posterior leaflet one. There was no difference in terms of age between the anterior and the posterior leaflet populations and the surgical indication was put very early, in asymptomatic patients in many cases. As I said, $70 \%$ of the patients were in functional class I or II. What I'd like to point out is that, in terms of selection, many of the other reports from the literature also deal with patients operated on just for degenerative disease. For example, those coming from Carpentier's group published in Circulation reported 20-year results of Carpentier's technique. Again, the patients selected had all undergone annuloplasty, so Carpentier's group also excluded some of the risk factors for mitral valve repair failure. Indeed it is a select population and this can explain the very good results we have, but this selection is applied to both groups.

In terms of survival, the results reported are those we had so far, probably because the patients were mostly asymptomatic and very young. Indeed, mortality rate has been very, very low.

Dr Miller. I have a word of caution about the echocardiographic studies. You had a late echocardiogram available in only $29 \%$ of the posterior leaflet group. I think that is a very serious limitation, which you've appropriately pointed out. However, it does make the comparison between anterior group and posterior groups shaky, if not fallacious, because you had a lot more echocardiographic studies in the anterior group. The article implies that you had $100 \%$ late echocardiograms in the anterior group. Was it really $100 \%$ and when was that late echocardiogram obtained in the anterior group? Do you have an average number of months or years postoperatively for the last echocardiogram in the anterior group?

Dr De Bonis. The mean time for the echocardiographic assessment performed in the ALP group is comparable with the mean duration of follow-up. When the patient came back, he had a follow-up outpatient clinic visit and underwent the echocardiographic assessment. This is very important to point out. In previous papers, one of the limitations of our studies has been that because the patients come from areas far and remote from where we are working, it has always been problematic to obtain echocardiographic assessments. Since we are very interested in the long-term results of the EE technique, in the last 5 years particularly we have tried to focus on getting these patients back for follow-up visits, and they have had at least one echocardiographic assessment. Thus the mean time of follow-up assessment in the ALP group was about $4 \frac{1}{2}$ years. Probably the median is around 3.2 years.

Since there were so many patients in the PLP group, 605 patients, we were able just to get echocardiographic assessments in only $30 \%$; the rest of the follow-up was telephone contact. We are aware of this limitation, which may have underestimated the failure rate in the PLP group.

Dr Miller. That's important information. It's 3 to 4 years for the anterior group, but the recurrence rate is still exceptionally low and that might be a result of your technique. For example, in Tirone David's paper presented at The American Association for Thoracic Surgery meeting 2 months ago, the freedom from recurrent 3 or $4+$ MR at 12 years was $65 \%$ to $67 \%$. These results are much inferior to yours. And in the anterior group, I think that's good echocardiographic follow-up.

You claim there is no mitral stenosis. I think that's doubtful because there is always a gradient at the time of the discharge echocardiogram if you use a ring. Do you have any exercise echocardiographic information available late? Because these are young people, they are going to exercise. Is there a functional mitral stenosis being generated?

Dr De Bonis. Yes, we have some echocardiographic assessment during exercise testing. We called back more than 30 patients for exercise stress tests (this has been published in the Journal of Heart Valve Disease in 2002). Eight of them were from the ALP group and the others from the bileaflet prolapse group. In none of these patients did we observe the development of important pulmonary hypertension or functional mitral stenosis. The mean gradient at the peak of the stress remained below $5 \mathrm{~mm} \mathrm{Hg}$ and the peak gradient was about $9 \mathrm{~mm} \mathrm{Hg}$. The pulmonary hypertension, which before the exercise was $22 \mathrm{~mm} \mathrm{Hg}$, came up to $29 \mathrm{~mm} \mathrm{Hg}$ but without reaching pathologic values. So, as far as we have been able to prove to this point, and also with this specific study, which was going to address this topic, we have no evidence that any functional mitral stenosis develops on exercise after repair performed in this way with a mean value of the valve area superior to $2.5 \mathrm{~cm}^{2}$.

Dr Miller. Thank you. That leads me to the next question. You claim, and it's important here that this is segmental, single scallop prolapse of either $\mathrm{A} 2$ or $\mathrm{P} 2$, and you now caution against a long EE suture repair. Does that mean you have abandoned the very long, 2, 3, $4 \mathrm{~cm}$, sewing the leaflets together which you have recently popularized in patients with Barlow and Marfan syndromes?

Dr De Bonis. In patients with Barlow disease, the good results of this population may be related exactly to this fact, that indeed they had segmental prolapse, segmental lesion, no important calcification. In the Barlow population, there usually is a preoperative area of the mitral valve, which can be around $10 \mathrm{~cm}^{2}$ or 9 to 10 . In that kind of population, we still perform a complete suture of A2 to P2, which can be 2-cm long. We don't have a problem in the very enlarged annulus of bileaflet prolapse in Barlow disease. In this setting, in ALP, when we had extensive prolapse or flail of A2 and A3 (we had 9 cases like this), we were concerned about inducing stenosis because the preoperative area was not comparable with that of bileaflet prolapse in Barlow disease. In that case we added artificial chordae. We did, let's say, a paracommissural EE repair, and then we put artificial chordae under A2. This is related 
to 9 patients we have operated on with this technique so far. That's our policy.

Dr Miller. Does that mean the both Barlow and Marfan diseases? I have seen Octavio Alfieri sew up not just $2 \mathrm{~cm}$ but 3 or 4 $\mathrm{cm}$ of these huge cauliflower Barlow's. Does that mean they are excluded from this experience?

Dr De Bonis. In this population, we never had such a long suture. Usually it was rather small.

Dr Miller. It was a different group, then. That means these are single Alfieri stitches, not 2 or 3 Alfieri stitches.

Dr De Bonis. We don't use separate stitches. We always use a suture, so I would rather talk about the length of the suture. In this population, I don't have a cutoff value, but I would say that we use around an 8-mm suture, something like that. In Barlow disease we use about a $2-\mathrm{cm}$ suture.

Dr Miller. It is a running suture and it's relatively small in these patients.

Dr De Bonis. Yes.

Dr Miller. Good. Finally, I think I have to disagree with you in one area, and again I congratulate you for clarifying your limitations. Your limitation slide made this discussion unnecessary. You cautioned that reoperation is not necessarily great in terms of indicating how much MR is recurring. I don't think it is at all accurate or reliable. Many of these patients can have a fair amount of recurrent MR, still remain asymptomatic, and certainly not require reoperation. In the absence of universal echocardiographic late follow-up, I think we have to interpret your durability results in the posterior group with extreme caution. Are you trying to get more patients back for late echocardiograms?

Dr De Bonis. Yes, actually we did this follow-up assessment in about 5 months, so that's what we were able to get. However, we are trying to know as much as possible about this population. We are trying to get back as many as possible of the patients with PLP in whom we might have underestimated the failure rate, since if one patient had recurrent MR but he did not undergo reoperation, we were not able to identify him.

Dr Miller. I hope that includes getting the operative notes from the redos. It's just like Carpentier. He has never had to redo one of his own repairs, but every single one of his colleagues in Europe has. None of your redos were done by you, but it would be valuable if you could get the operative notes and find out if there was suture dehiscence or what went wrong.

You should be very proud about a fine piece of work and a great presentation.

\section{Availability of Journal back issues}

As a service to our subscribers, copies of back issues of The Journal of Thoracic and Cardiovascular Surgery for the preceding 5 years are maintained and are available for purchase from Elsevier Inc. until inventory is depleted. Please write to Elsevier Inc.,Subscription Customer Service, 6277 Sea Harbor Dr, Orlando, FL 32877 , or call $800-654-2452$ or $407-345-4000$ for information on availability of particular issues and prices. 